Sajid Alfredo Herrera1

\title{
Hacia una reinterpretación de las ideas filosóficas en El Salvador El caso de los criollos
}

\section{Introducción}

En la mayoría de trabajos historiográficos sobre los acontecimientos de noviembre de 1811, en San Salvador, encontramos un señalamiento más o menos explícito sobre cuáles fueron las ideas filosóficas que acuerparon a los movimientos sociopolíticos lidereados por los criollos. En dichos trabajos la preocupación prioritaria del análisis se enfoca en la situación política, económica y social de la época, en donde el problema ideológico se convierte en un factor más de las complejas circunstancias vividas por peninsulares, criollos, indígenas y mestizos en la Provincia de San Salvador. Y aunque hace falta todavía mucho por estudiar sobre tales aspectos —denominados por algunos como "la base material"-, creemos que en torno al ámbito de las ideas se ha hecho muy poco. Por el momento no existen estudios sobre el desarrollo del pensamiento filosófico en los últimos días del régimen colonial salvadoreño (salvo, posiblemente, el del español Manuel Domínguez) ${ }^{2}$ ni tampoco estudios sobre cómo los criollos recepcionaron e hicieron uso de ese pensamiento dentro de las dinámicas sociales. Con lo que sí contamos son con trabajos abundantes sobre los sucesos de 1811 , quizás porque dentro de la historia oficial o dentro del imaginario nacionalista de muchos historiadores y escritores salvadoreños (e incluso algunos centroamericanos) es cuando los "padres de la patria" entran a escena".

En tal sentido, nos interesa en esta oportunidad detenernos en un aspecto muy concreto. Queremos proponer una interpretación del desarrollo de las ideas filosóficas en los criollos, especialmente durante las postrimerías del régimen colonial y en la otrora Provincia de San Salvador. Ello con la finalidad de ayudar a romper el nudo del antiguo debate sobre cuáles han sido las corrientes filosóficas que asumieron aquéllos y que les sirvieron de apoyatura teórica en sus intentos emancipadores. Pero sobre todo, para ver las cosas con más hondu- 
ra, pues no sólo interesa rastrear cuáles corrientes fueron acogidas por los criollos desde finales de la colonia y los propósitos de esa recepción, sino la manera én cómo las acogieron, y por lo visto éste es ya un problema de carácter más epistemológico que histórico. Por tanto, nuestra sugerencia reinterpretativa tendrá presente dos aspectos que consideramos por de pronto primarios: en primer lugar, revisar algunas características de la cultura criolla y en segundo, traer a cuenta la perspectiva procesual de la historia. Con ambos aspectos intentaremos abrir una ruta para repensar el problema de la recepción y utilización de las ideas filosóficas por parte de los criollos, dejándolo así abierto a futuras discusiones. Que quede claro, entonces, nuestro propósito: no intentamos agotar de una vez por todas esta problemática —muy compleja por cierto-. Más bien, deseamos dejar lanzadas ciertas claves de interpretación que requerirán a posteriori de mayores estudios y profundizaciones.

\section{Panorámica del problema}

Los estudios historiográficos a los que aludimos desde el principio apenas han rozado el debate ideológico criollo pues, como dijimos, no ha sido ese su interés. Pero este acercamiento marginal e, incluso, secundario, que algunos le han dado nos puede servir de mucho para comenzar con nuestra pequeña reflexión en tomo a este escabroso problema. En otros países la discusión se ha centrado en señalar o bien la coexistencia de diversas posturas o, simplificando, la preponderancia de dos de ellas en los movimientos hispanoamericanos de principios del siglo XIX: la Ilustración y la Escolástica. En el país, los diversos estudios en tomo a 1811 son los que más señalan la presencia de corrientes filosóficas en los conatos criollos por reinvindicar sus intereses. Por eso, creemos que es posible dividirlos en dos bloques interpretativos: en el primero estarían quienes estiman que han sido las ideas liberales e ilustradas las que ejercieron su inpacto teórico; en el segundo, aquellos para quienes fueron las tradicionales prácticas hispánicas del municipalismo y del denominado "populismo hispánico" del Siglo de Oro ibérico las que tuvieron su impacto mayor, aunque no niegan la presencia de ideas ilustradas. Los datos de los que parten ambos bloques para sostener sus aseveraciones son: el documento que los criollos sansalvadoreños elaboraron en noviembre de 1811, conocido como el acta-convocatoria; también, la educación universitaria recibida por algunos de ellos, quienes fungieron como los intelectuales de su grupo; la introducción de obras filosóficas o de literatura y el periodismo crítico. Además toman en cuenta las prácticas municipales que conservaron los criollos durante los tres siglos de colonia.

Es indiscutible la presencia de ideas ilustradas y liberales por aquellos días en Centroamérica. Pero también, es indiscutible la permanencia de ideas consideradas como "tradicionales", en donde se situarían el aristotelismo y las diversas escolásticas. Y es que la historia de las ideas repetidamente nos enseña que 
al interior de los grupos sociales no se dan posturas aceptadas en forma unánime. No hay al interior de los procesos sociales un acuerdo común en materia ideológica ni tampoco las corrientes de pensamiento desaparecen repentinamente. No obstante, la historiografía oficial nos ha mostrado a las posturas ideológicas de los "próceres" como las únicas o las más importantes frente a otras que se distanciaban de ellas. Han ocultado a estas últimas por convertirse en sinónimo de atraso u oscurantismo, alimentando así una visión positivista de las dinámicas del pensamiento. Por lo visto, entonces, el problema radica en cuál versión de la historia les interesa presentar a algunos o cuál de ellas les es más conveniente al nacionalismo que profesan.

Pensamos que no es adecuado continuar insistiendo en una visión triunfalista, lineal, homogénea y maniquea de las corrientes filosóficas en el país. Por eso queremos en esta oportunidad proponer ciertos componentes del ámbito cultural vivido, asumido y expuesto por los criollos con la finalidad expresa de ahondar más en el problema ideológico que nos ocupa. Sin marginar los condicionamientos "materiales", queremos preocuparnos ahora por algunos condicionamientos culturales de este grupo social, pues nos permitirán tener un primer acercamiento de cómo fueron apropiadas por los criollos las ideas filosóficas de la época. Lo cual no significa abrir una brecha entre lo socioeconómico y lo cultural, pues como se verá, son dos ámbitos íntimamente solidarios. Por otra parte, deseamos traer a cuenta un concepto filosófico que analiza la historia en términos de "procesualidad", porque nos puede ser muy útil para interpretar no sólo el devenir de los acontecimientos humanos, sino también el devenir de la historia de las ideas. Ese concepto nos ayudará a visualizar mejor el problema de la epistemologia criolla.

\section{Interpretaciones de las tendencias ideológicas criollas durante los suce- sos de 1811}

Antes de realizar nuestra propuesta sobre cuál podría ser un modo de interpretar el desarrollo de las ideas filosóficas en los grupos criollos de la Provincia de San Salvador, se hace necesario que echemos una mirada a la naturaleza de las corrientes filosóficas que, de acuerdo con los estudiosos del período de 1811, legitimaron las luchas reinvindicativas y los intentos de reorganización política de aquel grupo social. Ello, como lo veremos, será determinante para la reflexión que intentaremos realizar posteriormente.

Como apuntábamos arriba, es posible distinguir dos bloques interpretativos sobre las corrientes filosóficas que acuerparon a los acontecimientos de 1811. Veámoslos a continuación.

1. Las ideas ilustradas y liberales como el pensamiento predominante de los actores de los movimientos de 1811. Esta es la tesis que abrumadoramente comparten la mayoría de estudios y monografías sobre la época. Las ideas de autores 
franceses e ingleses (Locke, Montesquieu, Voltaire, Rousseau, etc.) así como el pensamiento liberal estadounidense, fueron - -de acuerdo con aquéllos- conocidas, asimiladas y expuestas por los criollos a través de diferentes canales: la formación universitaria, la labor de la Sociedad Económica de Amigos del País, la introducción de obras de pensadores ilustrados o philosophes a Centroamérica, el papel formativo de los periódicos, etc. A los estudiosos que afirman lo anterior, no se debe, por el hecho de clasificarlos en este bloque, de homogenizar por completo sus posturas. A pesar de compartir elementos comunes, sus diferencias en aspectos relacionados al tema saltan a la vista. Por ejemplo, Carlos Meléndez Chaverri sostiene que el acta-convocatoria de los criollos sansalvadoreños estaba escrita bajo un espíritu liberal, que denotaba un conocimiento de la Declaración de Independencia de Estados Unidos. Y los criollos que actuaron en dicho movimiento aspiraban a una independencia total del dominio español. Roberto Turcios, en cambio, maneja la tesis de que en ese momento había dos facciones entre los criollos. Una de ellas, lidereada por los principales dirigentes criollos de la ciudad, depositarios de ideas liberales, pero manteniendo una posición constitucionalista monárquica. La otra facción estaba representada por grupos de sectores populares, quienes llevaron a cabo las actividades más radicales, dirigidos por algunos criollos como los Aguilar y Mateo Antonio Marure ${ }^{4}$.

Otros estudiosos que se ubicarían aquí son: Alejandro Marure, para quien las invitaciones hechas a los demás cabildos de la Provincia por el de San Salvador eran liberales. Francisco Gavidia, quien era de la opinión de un republicanismo y democratismo ideológico que movió a los criollos sansalvadoreños. José Antonio Cevallos y Jorge Lardé y Larín expresan rotundamente la influencia de las ideas políticas de la Revolución francesa en los acontecimientos previos a la independencia. José Mata Gavidia y José Figeac, para quienes la labor ilustrada de la Universidad de San Carlos y del libro clandestino, respectivamente, desempeñaron una función decisiva en dichos movimientos. Jorge García Laguardia ha señalado que José Matías Delgado mostró en los primeros movimientos salvadoreños un espíritu enciclopedista al anteponer la soberanía de los ayuntamientos al poder real. Para Alejandro Marroquín, tanto los criollos como los mestizos estaban empapados del pensamiento liberal. En el caso de los criollos las fuentes eran: Montesquieu, Rousseau, los Girondinos y Maquiavelo. Por último, para Ramón López Jiménez y José Salvador Guandique, aunque los factores determinantes en los movimientos criollos fueron factores internos, no por ello desestiman la presencia —en Guandique, muy leve- de las ideas francesas y estadounidenses ${ }^{5}$.

2. Las ideas de la Alta Escolástica y las prácticas hispánicas tradicionales como factores influyentes en los criollos. Carlos Stoetzer, entre otros, ha afirmado que a la base de las revoluciones hispanoamericanas estaba tanto el pensamiento de la Alta Escolástica española (Suárez, Mariana...) como también la tradición ibérica del cabildo y no así la ilustración inglesa o francesa, que hasta 
mucho después ejercerán su influjo. Para este autor, el pensamiento neoescolástico no había desaparecido en las universidades americanas a pesar de la expulsión de los jesuitas; por el contrario, su huella en los criollos universitarios perduró hasta convertirse en el motor de sus revoluciones. Pero no sólo eso. La interpretación diversa de este pensamiento había conducido a que los grupos peninsulares y realistas criollos también se sirvieran de él para continuar legitimando la autoridad del rey cautivo y mostrar fidelidad a las juntas y a las Cortes de Cádiz. Los cabildos, por su parte, habían sido una "institución hispánica" heredada desde la reconquista e implantada en América -aunque se debilitó con el centralismo borbónico y luego se vigorizó con la inmigración de los vascos-, en los cuales la comunidad ejercía su derecho de participación ${ }^{6}$.

Entre los estudiosos e historiadores salvadoreños de la época no hemos encontrado ninguno que sustente esta tesis de Stoetzer a secas. Sin embargo, sí ha habido quienes hacen una interpretación más matizada, incorporando este elemento al de las influencias ilustradas. Uno de ellos es Roberto Molina y Morales. Él sostiene que en ausencia de Fernando VIl entraban a funcionar los cabildos y las juntas municipales, pues ellas eran depositarias de la soberanía. A su juicio, había renacido en tierras peninsulares y americanas el principio netamente español de invocar el nombre del rey, desconociendo la Regencia -dado que no representaba al monarca- y eligiendo los cabildos para que ejercieran la soberanía que había retomado a ellos. Esta doctrina antigua, enseñada por teólogos y filósofos del siglo de Oro español, había empapado a los criollos dirigentes de los sucesos de 1811. Rodolfo Barón Castro sostiene que en aquel momento había grupos con intereses distintos: unos pedían la independencia total y otros -influidos por las Instrucciones de José María Peinado- se aferraban a un constitucionalismo. Estos últimos fueron quienes llevaron a cabo un proyecto autonómico que, sin romper con la Península, deseaban establecer un gobierno propio y con legalidad en ausencia del monarca. Este era, según Barón Castro, el espíritu de mayor peso en los acontecimientos de 1811 y no la independencia absoluta o el republicanismo, aunque hayan existido dichas ideas. Por tanto lo que se hizo no fue más que glosar las Partidas de Alfonso X, manteniéndose en la más estricta tradición hispánica. Por su parte, Francisco Peccorini, si bien argumenta que la intención de los criollos insurgentes era discutir en un congreso de municipalidades la independencia de la Península, no desdeña la idea de que se utilizaron procedimientos netamente ibéricos en los sucesos de noviembre. Peccorini dice que se solucionó la crisis provincial de una manera "representativa" y "popular", en sintonía con las doctrinas jurídicas de los clásicos del Siglo de Oro español"

Ante estos dos bloques interpretativos, nuestra apreciación del problema nos lleva a tener en cuenta lo siguiente. En términos generales ambos tendrían sus aspectos valederos. Es indudable que hubo una recepción de ideas ilustradas en la región centroamericana de una manera profusa a finales del siglo XVIII y a través de diversos canales. El interés, entonces, de una historia de las ideas 
filosóficas ya no se centraría en demostrar solamente el hecho de que hubo influencias ilustradas en el territorio centroamericano, sino en determinar el carácter mismo de tales ideas en cuanto influjo o recepción y, además, los motivos para los que fueron utilizadas. En otras palabras, los autores situados en el primer bloque tienen el mérito de haber señalado la presencia de corrientes filosóficas, básicamente del ámbito norteamericano, inglés y francés en los movimientos criollos sansalvadoreños; sin embargo, ante esa variable incuestionable, lo que haría falta por resolver sería determinar, en la medida de lo posible, cuáles corrientes fueron acogidas y cuál fue la finalidad de su utilización; pero sobre todo $-\mathrm{y}$ eso es lo que nos interesa en nuestro tratajo- la manera como fueron acogidas, asimiladas y expuestas estas ideas por los intelectuales criollos.

Esto último nos lleva a valorar positivamente a los autores del segundo bloque interpretativo, porque la recepción de las ideas ilustradas por parte de la gran mayoría de criollos no conllevó un síntoma de liberalismo a secas o una posición ilustrada de carácter "afrancesado". A pesar de su disgusto con el régimen borbónico y a pesar de la presencia de "nuevas ideas", la inmensa mayoría de aquellos tenían configurada su percepción de las cosas bajo patrones típicamente hispánicos. En ese sentido, la epistemología de este grupo durante la época bien puede compararse con los rasgos de la Ilustración ibérica, pues en ella se evidenciaba una amalgama entre lo nuevo y lo antiguo, entre lo moderno y lo tradicional. Se hace necesario que revisemos ahora de manera somera algunas características de la cultura y mentalidad criolla.

\section{Algunas características de la cultura criolla}

Creemos que uno de los motivos por los cuales muchos de los estudiosos agrupados en el primer bloque del apartado anterior apuestan decididamente por una influencia liberal o ilustrada en los criollos, estriba en la tributación tradicional que se le hace en nuestros países a los denominados "próceres" o "padres de la patria". Una tributación que parte de un presupuesto sociológico muy cuestionable; por ende, este tipo de interpretación - muchas veces oficialista- no hace más que crear una historia típicamente maniquea tanto de los acontecimientos como de las ideas, olvidándose de la complejidad que rodea al hecho ideológico mismo.

Desde una perspectiva maniquea, el pensamiento escolástico, la tradición hispánica o la Escolástica del Siglo de Oro español, o bien representarían una etapa de oscurantismo y de atraso intelectual o simplemente no tendrían ninguna repercusión ideológica-práctica en los movimientos criollos en toda América. Sin embargo, no nos detendremos aquí a resolver este problema de si estas o aquellas corrientes de pensamiento estuvieron presentes. Ya insinuamos desde el inicio del artículo que de alguna manera el pensamiento "tradicional" hizo también lo suyo. Lo que sí queremos realizar en este apartado es una alusión a 
ciertos componentes de la cultura criolla con la finalidad de señalar, posteriormente, que toda historia de las ideas filosóficas deberá tener en cuenta el aspecto de las mentalidades colectivas y de las formas de vida, pues es ahí donde ellas transitan. Además, estas características culturales nos permitirán ver que la pretendida ilustración criolla no fue una mera recepción de ideas extranjeras, sino que conllevó un proceso epistemológico muy intrincado que bien puede interpretarse desde una perspectiva procesual de la historia. Ahora bien, sabemos que el fenómeno de la mentalidad de este grupo está todavía por trabajarse profusamente en nuestro país y en Centroamérica, pero podemos mencionar algunos elementos dentro de sus formas de vida o su imaginario que han quedado manifestados en escritos de la época de diversa índole o los conocemos a través de algunos estudios históricos.

1. Las redes familiares. Uno de estos componentes de la cultura criolla -cultura típicamente hispánica - es el fenómeno de las redes familiares o lazos familiares que unieron a muchos de ellos, cuya naturaleza puede atribuírsele a factores socioeconómicos, pero que en realidad también encontramos aspectos intrínsecamente culturales. En el caso de la ciudad de San Salvador, se constituyó una amplia red familiar entre los Arce, Delgado, Aguilar, Fagoaga, Lara, Aranzamendi, etc., de la cual surgieron prominentes políticos, ideólogos y funcionarios que estuvieron al servicio de los intereses de ese grupo. Las tradicionales historias, monografías o estudios de la época pre y postindependentista no han reparado lo suficiente en este fenómeno familiar. Más bien, han elaborado toda una apología de la pureza sanguínea y nobleza de aquellos criollos que intervinieron ya sea como ideólogos o activistas en los sucesos de 1811. Decantan, pues, estas historias en una defensa genealógica de los lazos familiares entre los Delgado, Arce o Aguilar y, a la vez, resbalan con sus interpretaciones en los mismos prejuicios hispánicos de aquella época.

Apuntar al problema de las redes familiares no debería llevar al hecho de asumir una visión aristocrática de las cosas por parte del historiador, emulando así a los criollos. Por el contrario, el estudio de este fenómeno de una manera adecuada permite interpretar mejor el por qué del imaginario criollo y el por qué de sus luchas sociopolíticas. Y es que la red familiar constituyó un conjunto de lazos o alianzas establecidas a través del matrimonio entre sus miembros, configurándose en un poder político, económico y religioso de la Provincia, aunque en momentos compartido con peninsulares u otros criollos allegados a aquellas familias (alianza mediante negocios). Estas redes fueron un patrón típico de la herencia hispánica en América, las cuales basaron su permanencia y compactación en la limpieza de sangre, la hidalguía, el status social, la posesión de lugares privilegiados y bienes, así como la creación de sus propios ideólogos con el fin de formar una visión de mundo muy propia ${ }^{y}$. 
2. La memoria del pasado. Otro aspecto de la cultura criolla -íntimamente ligado al anterior- es el de la conciencia de su pasado. En algunos escritos encontramos ef epíteto de "Españoles Americanos" con el cual se llamaban a sí mismos, enfatizándose esta identificación sobre todo a finales del régimen colonial. En el acta-convocatoria de noviembre de 1811, elaborada por los sansalvadoreños y que encontramos en los procesos de infidencia, aparece dicho término. También el vicario de San Vicente, Manuel Molina y Cañas, deja entrever su uso en un sermón pronunciado por aquellas fechas: "nuestra Nación está muy consternada, y el Rey, que tanto amamos y hemos jurado, también cautivo. (...) En semejantes circunstancias deberíamos pasar a unimos a nuestros hermanos los españoles de Europa para pelear con ellos a favor de la Iglesia y de la Nación"" . Por lo visto, este término evocaba la memoria de su pasado: los criollos se distinguían de la población debido a su procedencia hispánica. Su sangre, su genealogía, demostraba un privilegio y una distinción frente a los otros grupos que se encontraban bajo ellos en la jerarquía social. Así, por ejemplo, lo manifestó el cura de Panchimalco, José del Castillo: "me he gloriado siempre de tener en mis venas la sangre de Bernal Díaz del Castillo, uno de los conquistadores de estos países. Jamás bastardeará en mis sentimientos esta noble idea..."”.".

3. Sentimiento de pertenencia a la Nación y a su tierra. En la gran mayoría de criollos estuvo presente la conjugación de un sentimiento de pertenencia a la Nación española y de un sentimiento de arraigo a la tierra donde ellos nacieron. Y se debió en parte al trasplante en América, con ciertas particularidades, de las estructuras políticas de Castilla del siglo XVI, como lo fueron las organizaciones municipales. De esa manera, América pasó a formar parte de la monarquía plural española, cuya estructura estaba configurada piramidalmente. Dentro de la pirámide política del Antiguo Régimen español se encontraba ubicada, en la cima, la Monarquía; luego, descendiendo a los escalones medios, las Coronas de Castilla, León, Aragón, etc.; y en la base, los municipios. Los teóricos del Estado en la España barroca del siglo XVII fundamentaron esta idea de la Monarquía plural. Diego Tovar y Valderrama, por ejemplo, sostenía que la República era "un agregado de muchas familias que forman cuerpo civil, con diferentes miembros, a quienes sirve de cabeza una suprema potestad que les mantiene en justo gobierno..."11.

Las configuraciones políticas americanas en la época de la crisis monárquica todavía se encontraban estructuradas bajo la pirámide del Antiguo Régimen que, por aquellos días, no representó ninguna contradicción entre sus escalones. No obstante, la pirámide se invertía cuando se trataba del "sentimiento de arraigo". Así, el primer escalón de la identidad política americana (que en la pirámide anterior sería la base) estaba el sentimiento de pertenencia a un pueblo, villa o ciudad - la patria por antonomasia-; luego, se era de un Reino y al final (en la cúspide, de acuerdo con la pirámide anterior) se era miembro de la Nación o de la Monarquía. Se pertenecía, entonces, a la Nación, pero el sentimiento de perte- 
nencia a la patria, al suelo americano, a la localidad, era muy hondo, a tal punto que era primero y primario en la conciencia de muchos criollos. Este punto probablemente desempeñó una función decisiva a la hora de plantearse la independencia de España. Al respecto el historiador François-Xavier Guerra señala que una vez agudizados los recelos entre España y América (al no haber reconocido la primera, en la práctica, los derechos que tenían los habitantes de ultramar), el término de "españoles-americanos" se fue simplificando para muchos criollos en simplemente "americanos". No obstante, el hecho de que hubo cada vez más partidarios de una independencia absoluta con respecto de la Península, no opacó el que en la conciencia de muchos criollos perdurara la idea de pertenecer a una Monarquía plural. Prueba de ello fue la utilización por bastante tiempo del apelativo "españoles-americanos" en sus doumentos y discursos.

4. La tradición municipalista. Un cuarto elemento de la cultura criolla fue la tradición municipalista en cuanto forma de vida política. Esta tradición tuvo, tanto en la práctica como en la teoría, sus antecedentes en la Península. El municipalismo hispánico no redujo su entidad a una mera autarquía microsocial, sino a ser, en determinados momentos, parte activa y decisiva de un todo. En la vida práctica esta participación cobró realidad desde el año de 1188 , cuando los representantes de las ciudades acudieron a las Asambleas políticas. En la teoría, ya se encontraba fundamentada en las Partidas de Alfonso X el Sabio. En las Partidas se recomendaba a los reyes que para enmendar la legislación hubiese un acuerdo de éstos "con omes entendidos e sabidores de derecho, e que caten bien cuáles son aquellas cosas que se deben enmendar, e que esto lo faga con los más omes buenos que pudiese haber et de más tierras, porque sean muchos de un acuerdo" $\left(I^{\circ}, I, 17\right)$. Con ello, Alfonso X establecía la participación colectiva de los representantes de todas las ciudades en la toma de decisiones que incumbían al reino.

Así también se difundió en gran parte de la Europa medieval -incluyendo España - un principio que tenía un fuerte contenido democrático: Quod omnes tangit. Este principio, que tenía sus antecedentes en el derecho romano tardío (Codex de Justiniano) y en el derecho canónico (decretales de ciertos papas) y que encontró su base teórica en la Política de Aristóteles durante el siglo XIII, contribuyó en la Península a configurar un espíritu participativo. En el siglo XIV escribía el Canciller López de Ayala, un historiador castellano: "E sean con el Rey al consejo llegados/ Perlados, cavalleros, dotores e letrados,/ Buenos omes de villas, que hay muchos onrados;/ E pues a todos atanne, todos sean llegados"12. Este espíritu estuvo presente en diferentes Cortes durante los siglos XIII y XIV (Madrid, Burgos, Segovia, Zamora, Valladolid, etc.). No obstante, muchos historiadores han demostrado que desde los Reyes Católicos se puso coto a la autonomía y democratismo municipal -a través de inspectores reales o corregidores-, como también las Cortes perdieron paulatinamente su representatividad y su función de supervisar a la Corona a favor de las ciudades. La revolución 
comunera de Castilla (1520-1521) contra Carlos V, en la que se revivió el espíritu democrático-municipalista hispánico, terminó con la imposición del absolutismo de los Austrias. Por lo que ese espíritu medieval, de acuerdo con algunos historiadores, no tuvo ninguna vigencia, operativamente hablando, durante los siglos subsiguientes ${ }^{13}$. Mas, otros estudios históricos apuntan a que este imaginario se revivió durante el período de crisis que sufrió la Corona española a inicios del siglo XIX.

En efecto, ante la crisis monárquica sufrida por la invasión francesa a la Península, las ciudades españolas no tuvieron más opción que formar juntas provisionales y una Junta General para asumir la soberanía. Jovellanos fundamentó este fenómeno juntista desde el concepto de supremacia como poder que tiene la nación para conservar y defender legítimamente sus propias constituciones. Lo que se pretendió con el fenómeno juntista fue la restitución de las antiguas cortes hispánicas para elaborar una constitución escrita que garantizace la libertad, la propiedad y la seguridad de todos los ciudadanos y que, a la vez, pusiese coto a los abusos de un poder arbitrario; sin embargo, en un principio no hubo un consenso en el cómo debían configurarse dichas cortes. Para algunos ideólogos, revivir las cortes era revivirlas al modo antiguo, es decir, al modo estamental: participación de la nobleza y del clero. Para otros, la llamada ala "liberal" que, invocando siempre las Partidas de Alfonso X, creyeron conveniente que hubiese una participación más amplia: la participación popular. Además, fueron de la opinión que para restituir a las cortes era necesario incorporar todas aquellas ideas modernas que permitieran a España salir de su decadencia. Teóricamente este dilema - que no fue más que una muestra de la dialéctica "tradición-modernismo" dentro del espíritu español de la época - tuvo su síntesis con la fundamentación hecha por el ideólogo de las cortes, Francisco Martínez Marina ${ }^{14}$.

Como ha sostenido el historiador Francois-Xavier Guerra, en momentos en los cuales la Junta Central había sido desintegrada y se había formado el Consejo de Regencia, los criollos tuvieron dos opciones: ser fieles a la Regencia o asumir el poder por ellos mismos. Esto último fue el caso de la mayoría de ciudades americanas. Y eso es lo que sostuvo el clérigo sansalvadoreño Vicente Aguilar en una carta enviada al vicario general de Comayagua (11 de noviembre de 1811 ) en la que afirmaba que el procedimiento más conveniente ante un poder en crisis era "reclamar los títulos" al que todo pueblo tenía derecho para representar la soberanía: "conocieron [los americanos] que España estaba perdida...(...). La Suprema [Junta Central], instalada por sufragios de los reinos españoles de Europa y reconocidos por los de América, fue disuelta de un modo tumultuario, subrogándose por ella misma, sin legítimo poder y sin sufragio de los pueblos, la Junta de Regencia, que no podía por ningunos títulos exigir el homenaje que se debe al soberano". Y añade: "Por eso recurrió San Salvador a el medio de reclamar los títulos que le asisten a los pueblos para representar la soberanía, y por los medios muy decentes, pacíficos y tranquilos, en el modo 
extraordinario que corresponde, expresó su voluntad el día cinco de este [mes]..."15.

Konetzke sostiene que, si bien no hay mayores evidencias para afirmar que los ayuntamientos americanos fueron históricamente escuelas de autogobiemo -dado que en algunas ciudades americanas los criollos perdieron el interés por participar-, sí se convirtieron en la única institución política, en los momentos de crisis, que apelaron a la "representatividad" de la población y desde la cual la pequeña élite criolla asumió la soberanía. Sin embargo, en el caso de San Salvador parece que no existió ese desinterés del que nos habla Konetzke, pues desde finales del siglo XVIII hubo en la Provincia un forcejeo entre criollos y peninsulares por los cargos en el cabildo, tal como lo manifiesta Barón Castro en su obra citada.

5. La visión providencialista. La visión providencial de la vida y la historia fue otro componente de la cultura típicamente hispánica de los criollos. De acuerdo con ésta, los planes humanos ya están previstos por la Providencia de Dios, por lo que a los hombres les tocará llevar a cabo tales designios. Esta visión providencial impregnó el mundo cotidiano colonial dado que se constituyó en una realidad abierta a lo ultraterreno. Por eso, Manuel García Morente ha dicho que el hombre hispánico no consideraba la vida eterna como la meta a la cual llegará el individuo al término de su experiencia vital, sino como el fin de cada instante de su vida. El orientar su vida hacia Dios, hacía que la experiencia diaria de cada individuo, dentro de ese mundo providencialista, estuviese colgada del "puerto sobrenatural"16. Ahora bien, debemos aclarar que aunque este providencialismo criollo tenía hondas raíces hispánicas, a nivel de práctica religiosa estuvo de alguna manera influido por una serie de factores que no eran propiamente peninsulares sino que procedían de elementos de las culturas indígenas e, incluso, en algunos casos, de las culturas africanas ${ }^{17}$.

Con todo, la creencia criolla sansalvadoreña en el providencialismo ha quedado evidenciada tanto en escritos como en pronunciamientos políticos y religiosos. José Matías Delgado, por ejemplo, en su prédica del 22 de diciembre de 1811 sostenía: “...os habla (...) un hombre de cuyo amor tenéis repetidas pruebas, a quien conocéis desde que nació, que está impuesto de vuestros derechos, que sabe cuáles son sus límites, y que se haya destinado por la providencia para conciliarlos con el bien general..."; por su parte, Isidro Menéndez en un discurso pronunciado el 15 de septiembre de 1846, sostenía: "Llegado el tiempo prefijado por la Divina Providencia y al favor de las luces del siglo que jeneralizaron las bellas máximas de eterna justicia sobre los derechos del hombre en sociedad (...) proclamaron nuestros padres la independencia, arrastrando los calabozos, los destierros y los patíbulos"'ا8. Basten estos dos casos para damos cuenta de la síntesis de la cual venimos hablando. 
Estos cinco, componentes de la cultura criolla que hemos esbozado nos muestran las raíces hispánicas de la misma. Como dijimos en un principio, no era nuestra intención ni realizar un estudio pormenorizado de tales componentes ni afirmar que sólo ellos caracterizarían la forma de vida y las creencias de los criollos, especialmente durante los últimos años del período colonial. Empero, tenerlos en cuenta nos permitirá comprender que si bien los criollos acogieron ciertas ideas ilustradas y liberales, lo hicieron desde su propia visión de mundo. Basta observar, por ejemplo, el extracto del sermón que pronunció Isidro Menéndez en el cual veíamos cómo su concepción providencial se conjugaba con la apelación a la época de las Luces (y todo lo que ella representaba en tanto época de reinvindicación de derechos humanos). O cómo muchos criollos sansalvadoreños creyeron conveniente asumir la soberanía durante la crisis monárquica ba jo la tradición municipalista, siendo la mayoría de ellos simpatizantes de ideas ilustradas, como era el caso de José Matías Delgado. Tampoco las prácticas matrimoniales, el sentimiento de pertenencia a una monarquía plural y la memoria de su pasado se constituyeron en un freno a la acogida de los nuevos pensamientos filosóficos. Más bien, nos muestra que estamos siempre ante sujetos o grupos humanos con una tradición y una mentalidad de por medio, la cual no podemos eludir. Las ideas filosóficas deberán, en ese sentido, considerarse como partes de un conjunto ideológico o de una forma de vida que no escapa a las coordenadas espacio-temporales.

Ya algunos historiadores nos han mostrado en sus trabajos sobre las ideas filosóficas en el ámbito académico hispanoamericano, que sí fue posible un acoplamiento entre lo "moderno" y lo "antiguo." A las tradicionales ideas escolásticas en materia metafísica, lógica y política se acoplaron conceptos de procedencia cartesiana, leibniziana, newtoniana, entre muchos otros. No debemos, entonces, abrir brechas entre las temporalidades. Quizás, para evitar esa tentación y acercarnos a ese fenómeno de síntesis entre lo antiguo e innovador, nos sirva de mucho la consideración procesual que algunos pensamientos filosóficos mantienen en torno a la historia de la humanidad. Pasemos ahora a completar nuestras notas con una breve incursión en el campo de la filosofía de la historia.

\section{La historia del pensamiento entendida como proceso}

Hay un hecho innegable a la hora de considerar la historia de la filosofía: las ideas filosóficas no deben presentarse ni concebirse desvinculadas de los procesos económico-sociales en los cuales ellas se originan. Visto de esa manera, las ideas filosóficas tienen su origen en individuos o en comunidades de investigadores e ideólogos, quienes son deudores de los condicionamientos materiales existentes en cada época histórica. Este aspecto ya ha sido recalcado rotundamente por diversas tradiciones filosóficas contemporáneas, por lo que nos parece 
muy familiar su énfasis. La tradición marxista, por ejemplo, nos advierte que no son las ideas las que dirigen o mueven la historia, sino los hombres, quienes, inmersos en los procesos socioeconómicos, son los productores de aquéllas. Bajo esos supuestos tan familiares en nuestros días no nos parece entonces extraño concebir al pensamiento ubicado en sus propias coordenadas espacio-temporales o materiales. Pero resulta que el pensamiento filosófico no sólo se ubica en un ámbito socioeconómico: se desliza, transita, recorre el interior de las mentalidades colectivas. Y de esa manera, la filosofía se convierte en deudora tanto de las condiciones materiales como de los imaginarios colectivos. Quizá ha sido Foucault quien, siguiendo en parte a Nietzsche, nos lo haya reiterado sutilmente al realizar sus investigaciones sobre la formación del yo en occidente o al realizar sus estudios sobre la sexualidad o del nacimiento de la prisión y la clínica.

El que la filosofía transite en una mentalidad asumida por ciertos individuos nos permite situar mejor el problema de la epistemología criolla. Cuando los estudios del primer bloque interpretativo — vistos en el tercer apartado- afirmaban que una de las fuerzas que coadyuvaron a la lucha criolla contra el régimen colonial fue el pensamiento liberal o ilustrado, no repararon en dos hechos que son mucho más complejos de lo que se cree: no se trataba de individuos cuya constitución esencial resultaba ser una tabula rasa, sino de individuos que desde su tradición o mentalidad colectiva asumieron, asimilaron y dieron cauce a las ideas "modernas" acogidas desde finales del siglo XVIII. Además, no se trata de interpretar la historia de las ideas filosóficas desde una perspectiva "sucesiva", pues de serlo así terminaría anulando ese proceso de recepción y asimilación del cual estamos hablando. Ahora bien, no se vaya a pensar que le estamos otorgando una centralidad absoluta al problema cultural por encima de otras variables o que creemos en una mentalidad colectiva como "espíritu del pueblo" rectora de las vidas y acciones humanas.

En algo parecido tiende a caer José Mata Gavidia en su interpretación sobre los procesos independentistas centroamericanos. Gavidia -historiador de las ideas en la Universidad de San Carlos de Guatemala - sostuvo que los aspectos socioeconómicos, si bien fueron elementos que desempeñaron una función necesaria en los movimientos centroamericanos por su emancipación, no fueron los suficientes —o en palabras de él: fueron "concomitancias", fue lo "circustanciado", pero no lo auténtico del problema- A su juicio, la condición sine qua non de tales movimientos estaba en la conciencia y vivencia de querer ser independientes, en una conciencia de nacionalidad y en una nueva cultura fomentada por la enseñanza universitaria que fue asumida por una clase dirigente. En una palabra, era un sentimiento de independencia que venía de adentro, del "yo individual y colectivo"'y . Por nuestra parte creemos que entre lo cultural y lo socioeconómico existe una co-determinación en la cual bien pueden haber momentos en los que uno tiene un tiempo de dominancia sobre el otro y viceversa, pero sin que esa dominancia rompa con la estructuralidad que integran ambos. 
Volviendo al punto que nos ocupa, luego de esa oportuna digresión, debemos decir que la historia humana $-y$, por ende, la historia de las ideas - no consiste en una sucesiơn lineal en donde lo pasado queda aniquilado por el presente. Indudablemente muchos de los autores agrupados en el primer bloque presuponían una historia lineal y triunfalista en sus análisis: las nuevas etapas o los nuevos estadios son precisamente "nuevos" porque en su naturaleza no hay rastros de las etapas que les han precedido. Habría, entonces, una anulación de lo anterior, siguiendo la misma dinámica la historia de las ideas: al estadio del oscurantismo le sucede el estadio de las Luces. Como puede observarse, asistimos de esta manera a una perspectiva de la historia de carácter sucesiva, donde cada generación es esencialmente novedosa a su predecesora. Pero, en realidad, la historia de la humanidad y la historia del pensamiento muestran otra dimensión muy distinta. Y es que cada etapa y generación "arrancan de" una etapa anterior, es decir, conservan en su interior aspectos pretéritos aunque de una forma novedosa. Es lo que Zubiri ${ }^{20}$, por ejemplo, ha denominado el carácter procesual de la historia, pues para este filósofo vasco, ésta consiste en un "proceder-de" y en un "proceder-a". Cada mundo presente (entiéndase por él a lo material, a lo ideológico, a lo social, personal, etc.) estaría "apoyado en" el mundo pretérito, de tal manera que el movimiento histórico ya no sería sucesivo sino procesual.

En tal sentido, la recepción y utilización de ideas ilustradas por parte de los criollos, que constituiría una nueva etapa dentro del desarrollo del pensamiento en Hispanoamérica, estaría apoyada en una etapa anterior. Y es más, esta última quedaría integrada de alguna manera en la primera. De ese modo, las conjugaciones entre la visión providencialista de la historia con el aporte humanista de la época de las Luces, tal como nos lo mostraba Isidro Menéndez, fueron posibles. Tal vez sea oportuno en este momento citar algunas ideas de José Ortega y Gasset que vendrían a confirmar nuestra argumentación. Dirá Ortega, refiriéndose al caso de Argentina (pero que bien puede aplicarse al mundo criollo en Hispanoamérica durante el siglo XIX), que si bien aquélla se alejó de la Metrópoli en búsqueda de horizontes culturales distintos, como el francés, no por ello enterró su pasado hispánico. "Ese apartamiento de España - sostiene el filósofo ibérico- y de su cultura se produjo sólo en el estrato de la vida colectiva (...) que depende de la voluntad de los hombres. Pero en la persona, como en la nación, la voluntad opera sólo en la superficie: las zonas profundas del ser no le obedecen... Argentina había sido España y lo que alguien fue, sigue inevitablemente siéndolo (...) como el hombre maduro es maduro gracias a que sigue actuando en él su juventud... La España que la Argentina fue, perdura, pues, quiérase o no, en el fondo más soterraño de vuestro ser y sigue allí, tácita, operando sus secretas químicas; por eso (...) sigue influyendo bien que en forma menos visible, en forma como subrepticia, atmosférica o de difusa ósmosis"21. Como vemos, para Ortega y Gasset no hay ruptura en la historia, sino continuidad; pero entiéndase a ésta de una manera renovada. 
La perspectiva zubiriana no ha sido entonces la primera en recalcar la procesualidad de la historia. Ya en Hegel encontramos un antecedente para la filosofía contemporánea de enorme importancia. Sin embargo, para el alemán el proceso es concebido desde un supuesto racionalista que termina en última instancia marginando los avatares propiamente materiales: muestra, en fin, el desarrollo del Absoluto, del Espíritu. Zubiri, por su parte, concebirá la procesualidad de la historia como una procesualidad personal y social, apoyada en el sustrato físico y biológico. Dicho en otros términos, será un dinamismo donde intervienen diversos momentos en los que los niveles posteriores han sido "desgajados exigencialmente" de los anteriores, pero que a la vez se encuentran "subtendidos" en los últimos. Además, la historia será un proceso de transmisión tradente, es decir, de transmisión de formas de estar en la realidad. Y esto es sin lugar a dudas lo peculiar de la perspectiva zubiriana. Sin embargo, para nuestros propósitos no sólo es útil una visión de procesualidad sin más. Debemos, también tener presente junto a esa dimensión una consideración del tiempo como un proceso no homogéneo, pues de lo contrario podríamos volver a caer, inevitablemente, en una interpretación lineal del desarrollo del pensamiento. El tiempo no homogéneo ${ }^{22}$ indica la existencia de tiempos múltiples que se desarrollan en diferentes planos dentro de un mismo período histórico dado que cada individuo o cada grupo construye su propia temporalidad, su propio mundo.

Esta construcción de la propia temporalidad nos remite, en el ámbito de las ideas, al hecho de la diversidad de posturas en una misma época, de tal modo que para nuestro estudio significaría comenzar a comprender desde ahora al desarrollo del pensamiento en términos plurales y no monolíticamente. La consideración del tiempo no homogéneo nos permite descubrir, entonces, la coexistencia de corrientes filosóficas como las escolásticas y los pensamientos ilustrados durante las postrimerías del régimen colonial e, inclusive, durante todo el siglo XIX. Además, nos revela que dentro de aquellos que se consideraron ilustrados habían unos que eran monárquicos constitucionalistas, independentistas, republicanos, etc. A final de cuentas, pluralidad. En efecto, si bien hubo puntos de carácter cultural, vital o teórico que la mayoría de criollos compartieron, en otros se distanciaron profundamente.

\section{Epílogo}

Hemos querido lanzar en esta oportunidad algunas intuiciones que requerirán de mayores aproximaciones. Hemos intentado proponer algunos elementos que consideramos claves para repensar una vía de interpretación en tomo al desarrollo de las ideas filosóficas en el país y sobre todo en el caso de los criollos. Sabemos que hacen falta otros elementos por considerar como, por ejemplo, la característica fragmentaria del discurso cargado de ideas filosóficas, que se patentiza no sólo en el país sino en casi toda Hispanoamérica. Pero aquí nos interesó señalar un aspecto concreto: que ante el influjo de las corrientes filosó- 
ficas ilustradas y liberales, el modo de aprehender, asimilar y responder ante la situaciones por parte de los criollos no se debió meramente a un proceso de acogida de aquéllas, sino a un aspecto de mayor radicalidad que bien podría denominarse como la epistemología criolla. Y es que todo apunta a un proceso de síntesis entre lo tradicionalmente hispánico y las nuevas ideas de carácter ilustrado. Los modos de habérselas de los criollos con sus circunstancias fueron, entonces, modos amalgamados entre lo tradicional y lo moderno, entre lo antiguo e innovador. Tener presente, pues, este problema epistemológico nos permitirá comprender mejor el carácter o la naturaleza misma de la historia de las ideas filosóficas en nuestro país durante gran parte del siglo XIX.

\section{Notas}

1. Jefe del Departamento de Filosofía de la Universidad Centroamericana "José Simeón Cañas" (UCA).

2. M. Domínguez, "La filosofía como fundamentación teórica de la independencia y como iluminación del horizonte de una nueva sociedad", ECA 431, 1984 pp. 639654. Este artículo de Domínguez corresponde a la primera parte de un trabajo inconcluso titulado "Historia de la filosofía en El Salvador. Siglo XIX" (1980), que se encuentra mimeografiado.

3. Por ejemplo, M.A. Fagoaga, Primera independencia de El Salvador. La revolución de 1811, 4 de noviembre-3 de diciembre, y el primer gobierno autónomo, San Salvador: Facultad de Humanidades de la Universidad de El Salvador, 1954.

4. C. Meléndez Chaverri, El presbitero y doctor don José Matias Delgado en la forja de la nacionalidad centroamericana, San Salvador: Ministerio de Educación, 1961, pp. 133-135; R. Turcios, Los primeros patriotas. San Salvador 1811, San Salvador: Ediciones Tendencias, 1995, pp. 214-228.

5. A. Marure, Bosquejo histórico de las revoluciones de Centro América desde 1811 hasta 1834, T.I., Guatemala: Tipografía El Progreso, 1877, p. 14; F. Gavidia, Historia moderna de El Salvador, San Salvador: Imprenta Meléndez, 1917, p. 74; J.A. Cevallos, Recuerdos salvadoreños, T. II, San Salvador: Imprenta Nacional, 1919, p. 5; J. Figeac, Recordatorio histórico de la República de El Salvador, San Salvador: Talleres Gráficos Cisneros, pp. 55-56; J. Mata Gavidia, "La Universidad de San Carlos en el movimiento de la Independencia", en C. Meléndez (Comp.), Textos fundamentales de la independencia centroamericana, San José: EDUCA, 1971, pp. 187-196; J.M. García Laguardia, Origenes de la democracia constitucional en Centroamérica, San José: EDUCA, 1976, p. 46; A.D. Marroquín, Apreciación sociológica de la independencia salvadoreña, San Salvador: Universidad de El Salvador, 1964, pp. 56-57; R. López Jiménez, José Matias Delgado y de León. Su personalidad, su obra y su destino, San Salvador: Ministerio de Educación, 1961, pp. 2124; J.S. Guandique, Presbitero y Doctor José Matias Delgado, San Salvador: Ministerio de Educación, 1961, pp. 257-259.

6. C. Stoetzer, "Independencia y dependencia en el pensamiento político hispanoamericano", en Stromata $\mathbf{N}^{\circ}$ 3-4, julio-diciembre, 1976, pp. 383-391; del mismo autor: El pensamiento político en la América española durante el período de la emancipación (1789-1825), T. I., Madrid: Centro de Estudios Constitucionales, 1966, pp. 65- 
98; Las raices escolásticas de la emancipación de la América española, Madrid: Centro de Estudios Constitucionales, 1982, pp. 17 y ss; 21 y ss.

7. R. Molina y Morales, Los precursores de la independencia, San Salvador: Editorial Delgado, 1985, pp. 74-77; R. Barón Castro, José Matías Delgado y el movimiento insurgente de 1811, San Salvador: Ministerio de Educación, 1962, pp. 69-70; 100101; 175-192; F. Peccorini Letona, La voluntad del pueblo en la emancipación de El Salvador. Un estudio sobre las relaciones del pueblo con los próceres de la independencia y en la anexión a México, San Salvador: Ministerio de Educación, 1972, pp. 15; 35; 49-50; 59-60.

8. Sobre los lazos familiares sansalvadoreños ver M.A. Gallardo, Papeles históricos, Santa Tecla: Colegio Santa Cecilia, 1964, pp. 118-119; sobre las características de las redes familiares ver M.E. Casáus Arzú, "El papel de las redes familiares en la configuración de la élite de poder centroamericana. (El caso de la Familia Díaz Durán)", en Realidad 42, 1994, pp. 973-982; D. Balmori; S.F. Voss; y M. Wortmann, Las alianzas de familias y la formación del país en América Latina, México: FCE, 1990, pp. 42-51; 73-108; 253-254.

9. M.A. García, Diccionario histórico enciclopédico de la República de El Salvador. El Doctor José Matías Delgado, T. I., San Salvador: Imprenta Nacional, 1932, p. 490.

10. Citado en F. Gavidia, op. cit., p. 100.

11. Citado en J.L. Abellán, Historia crítica del pensamiento español, T. III: Del Barroco a la Ilustración, Madrid: Espasa-Calpe, 1988, p. 69; en torno a las identidades políticas y culturales americanas ver F-X Guerra, "Identidades e independencia: la excepción americana", en Cuadernos de historia latinoamericana $\mathrm{N}^{\circ} 2,1994$, pp. 96 y ss.

12. Citado en J.A. Maravall, Estudios de historia del pensamiento español, Madrid: Ediciones Cultura Hispánica, 1973, p. 182. En torno a las influencias de las Partidas y al espíritu participativo tardomedieval español, véanse en la obra anterior las páginas 144-149; 175-190.

13. J. Pérez, La revolución de las comunidades de Castilla (1520-1521), Madrid: Siglo XXI editores, 1979, pp. 64 y ss; J. Lynch, España bajo los Austrias. I: Imperio y Absolutismo (1516-1598), Barcelona: Península, 1975, pp. 13-14; 253-259. Para el caso de América ver R. Konetzke, Historia Universal. América Latina II: La época colonial, México: Siglo XXI editores, 1995, pp. 128-134.

14. J.L. Abellán, Historia crítica del pensamiento español, T.IV: Liberalismo y Romanticismo (1808-1874), Madrid: Espasa-Calpe, 1984, pp. 90-118; J.L. Aranguren, Obras Completas. Vol. 4: Moral, sociología y política I, Madrid: Trotta, 1996, pp. 55-58; sobre la influencia de los neoescolásticos en los liberales españoles ver L. Díez Del Corral, El liberalismo doctrinario, Madrid: Instituto de Estudios políticos, 1973, pp. 459 y ss.

15. Citado en R. Molina y Morales, op. cit., p. 174.

16. M. García Morente, "Ideas para una filosofía de la historia de España", en Obras Completas, II (1937-1942) Vol. I, Barcelona: Anthropos, 1996, p. 411.

17. H-J. Prien, La historia del cristianismo en América Latina, Salamanca: Sígueme, 1985 , p. 285.

18. El discurso de Delgado está en S. Salvatierra, Contribución a la historia de Centroamérica, Managua: Tipografía Progreso, 1930, p. 388. El subrayado es nuestro; el 
discurso de Menéndez se encuentra en el periódico "El Salvador Rejenerado", San Salvador 25 de septiembre de 1846, $\mathbf{N}^{\circ} 40$, p. 40, en A. Tarracena Arriola (Comp.), Periódicos de la primera mitad del siglo XIX, Centro de Estudios Mexicanos y centroamericanos, 1996. Obsérvese que el discurso de Menéndez fue pronunciado años después de la independencia. Ello confirma el hecho de que este espíritu de síntesis pervivió mucho después del régimen colonial.

19. J. Mata Gavidia, "Lo auténtico y lo circunstanciado en la independencia de Centro América", en C. Meléndez (Comp.), Textos fundamentales..., pp. 198-207. Otros estudiosos de la época sostendrán que la función principal en los movimientos criollos lo tuvieron los procesos socioeconómicos, siendo las ideas un factor de acompañamiento y legitimación. Ver J. Lynch, The spanish-american revolutions, 18081826, New York: W.W. Worton \& Company, 1973, p. 28.

20. X. Zubiri, Siete ensayos de antropología filosófica, Bogotá: Universidad de Santo Tomás, 1982, pp. 124-125.

21. J. Ortega y Gasset, Meditación del pueblo joven, Buenos Aires: Emecé Editores, 1958, p. 40.

22. Ver M. Cruz, Filosofia de la historia. El debate sobre el historicismo y otros problemas mayores, Barcelona: Paidós, 1991, p. 161. 